\title{
Total anomalous pulmonary venous return Prenatal damage to pulmonary vascular bed and extrapulmonary veins
}

\author{
SHEILA G HAWORTH \\ From the Department of Paediatric Cardiology, Institute of Child Health, Guilford Street, London
}

SUMMARY To investigate the possibility that pulmonary vascular disease may be present at birth in children presenting with obstructed total anomalous pulmonary venous return in the neonatal period, pulmonary vascular structure was analysed in the lungs of six babies who died during the first week of life. Five babies had infradiaphragmatic total anomalous return and in one the pulmonary veins drained to the right atrium. In all cases mean percentage arterial medial thickness was greater than is normal at 5 hours. The most striking change occurred in the intra- and extrapulmonary veins. Within the lung, in all six cases mean percentage vein wall thickness was significantly increased and in two cases intimal proliferation occurred in preacinar veins. The extrapulmonary veins were generally small in all five cases of infradiaphragmatic total anomalous pulmonary venous return, microscopically were abnormally thick walled in four, and showed intimal proliferation in three cases. In two cases the descending vertical vein was severely narrowed or occluded.

A prenatal increase in intrapulmonary arterial and venous muscularity may encourage episodic pulmonary hypertension in the immediate postoperative period. In the infradiaphragmatic type of anomaly, prenatal structural changes in the extrapulmonary veins may predispose to the later development of pulmonary vein stenosis despite a successful surgical repair.

The mortality rate for correction of total anomalous pulmonary venous return has improved considerably during the past 10 years. Two recent series quote a hospital survival rate of $87 \%$ and $88 \% .^{2}$ Age is becoming less important as a determinant of survival probably because of earlier patient referral and improvements in surgical technique. In one recent study age was shown to have no effect on survival. ${ }^{1} \mathrm{At}$ The Hospital for Sick Children, Great Ormond Street, however, during the past five years the hospital survival rate for children aged 1 week or more was $87 \%$ while for those less than 1 week of age it was only $36 \%$. The higher mortality in the younger age group may perhaps be the result not of age itself but of other factors associated with the early development of pulmonary venous obstruction. Little is known about the state of the pulmonáry vascular bed at birth in these babies,

SGH is supported by the British Heart Foundation.

Accepted for publication 3 August 1982 but, in slightly older patients, pulmonary vascular disease has been considered to be an important determinant of survival. ${ }^{3-5}$

In order to investigate the possibility that pulmonary vascular disease may be present at birth in children presenting with obstructed total anomalous pulmonary venous return in the neonatal period, pulmonary vascular structure has been analysed in the lungs of six babies who died during the first week of life. Previous pathological studies on the lung in total anomalous pulmonary venous return have concentrated on pulmonary arterial structure. ${ }^{56}$ Recently, however, there have been several clinical reports of pulmonary vein stenosis.developing in patients who have had an apparently successful repair of the anomalous venous drainage. ${ }^{12}$ The stenosis developed in the pulmonary vein, proximal to the anastomosis between the venous confluence and the left atrium, and was not related to the suture lines. In the present study, therefore, the structure of the intra- and extrapulmonary veins has been analysed in addition to that of the arteries. 


\section{Clinical features}

All the babies presented with cyanosis during the first six hours of life. None had a murmur save case 5 in whom a soft systolic murmur was heard at the upper left sternal border. In cases 2 and 6, the liver was enlarged below the right costal margin by 2 and $5 \mathrm{~cm}$, respectively. The electrocardiogram showed signs of right ventricular hypertrophy in all except case 4 . In all cases the chest radiograph showed a heart of normal size. The lung fields had a fine granular appearance in all save cases 1 and 4 . At cardiac catheterisation the pulmonary arterial pressure was equal to, or exceeded, the systemic arterial pressure and the arterial oxygen saturation was similar in the pulmonary artery and aorta in all cases (Table). In five cases pulmonary angiography showed total anomalous pulmonary venous return to an infradiaphragmatic site, except in case 4 , where the left upper lobe only drained into a left superior vena cava. In the remaining case (case 5) a diagnosis of total anomalous pulmonary venous return to the right atrium was made by two dimensional echocardiography.

Four babies died at or soon after surgical repair of the anomaly at between 1 and 6 days of age. Cases 4 and 5 died before operation could be attempted. The interatrial defect was a secundum atrial defect found at operation in cases 2,3 , and 6 , and a stretched foramen ovale was present in cases 1,4 , and 5 .

At necropsy, in four of the cases with infradiaphragmatic total anomalous pulmonary venous return, the descending vertical vein entered the porta hepatis, and in the fifth case (case 1) it entered the inferior gastric vein. The ductus arteriosus was or had been patent in all cases, having been ligated in those patients submitted to operation. Case 1 also had a small subaortic ventricular septal defect measuring $3 \mathrm{~mm}$ in diameter and partial juxtaposition of the left atrial appendage. In all cases the left ventricle was of normal size.

\section{Pathological studies}

The pulmonary vessels were injected in only two patients, cases 4 and 5 . The pulmonary arteries were injected under pressure with a barium sulphate gelatin mixture in the right lung of case 4 and in the middle and lower lobes of the right lung in case 5. The pulmonary veins of the right upper lobe in case 5 were also injected using the same technique. The lungs of these two cases were fixed by injecting the airways with formol saline at constant pressure. Blocks of tissue $1 \mathrm{~cm}$ square were taken for histological examination from the lungs of all cases, as indicated in Fig. 1.

Table Clinical data

\begin{tabular}{|c|c|c|c|c|c|c|c|}
\hline \multirow{2}{*}{$\begin{array}{l}\text { Case } \\
\text { No. }\end{array}$} & \multirow[t]{2}{*}{ Diagnosis } & \multirow{2}{*}{$\begin{array}{l}\text { Age at } \\
\text { cardiac } \\
\text { catheterisation } \\
\text { (d) }\end{array}$} & \multirow{2}{*}{$\begin{array}{l}\text { Pulmonary } \\
\text { arterial } \\
\text { or right } \\
\text { ventricular } \\
\text { pressure } \\
(\text { mmHg })\end{array}$} & \multirow{2}{*}{$\begin{array}{l}\text { Systemic } \\
\text { arterial } \\
\text { or left } \\
\text { ventricular } \\
\text { pressure } \\
(\mathrm{mmHg})\end{array}$} & \multicolumn{2}{|c|}{$\% \mathrm{O}_{2}$ saturation } & \multirow{2}{*}{$\begin{array}{l}\text { Age at } \\
\text { death } \\
\text { (d) }\end{array}$} \\
\hline & & & & & $\begin{array}{l}\text { Pulmonary } \\
\text { artery }\end{array}$ & Aorta & \\
\hline \multirow[t]{2}{*}{1} & \multirow{2}{*}{$\begin{array}{l}\text { Infradiaphragmatic } \\
\text { total anomalous } \\
\text { pulmonary venous } \\
\text { return }\end{array}$} & \multirow[t]{2}{*}{1} & $85 / 50$ & $75 / 50$ & \multirow[t]{2}{*}{60} & \multirow[t]{2}{*}{62} & \multirow[t]{2}{*}{1} \\
\hline & & & $\overline{60}$ & $\overline{60}$ & & & \\
\hline \multirow[t]{2}{*}{2} & \multirow{2}{*}{$\begin{array}{l}\text { Infradiaphragmatic } \\
\text { total anomalous } \\
\text { pulmonary venous } \\
\text { return }\end{array}$} & \multirow[t]{2}{*}{1} & $40 / 30$ & $45 / 35$ & \multirow[t]{2}{*}{62} & \multirow[t]{2}{*}{65} & \multirow[t]{2}{*}{2} \\
\hline & & & $\overline{33}$ & $\overline{38}$ & & & \\
\hline \multirow[t]{2}{*}{3} & \multirow{2}{*}{$\begin{array}{l}\text { Infradiaphragmatic } \\
\text { total anomalous } \\
\text { pulmonary venous } \\
\text { return }\end{array}$} & \multirow[t]{2}{*}{3} & \multirow[t]{2}{*}{$55 / 3$} & $59 / 35$ & \multirow[t]{2}{*}{64} & \multirow[t]{2}{*}{67} & \multirow[t]{2}{*}{3} \\
\hline & & & & $\overline{43}$ & & & \\
\hline \multirow[t]{2}{*}{4} & \multirow{2}{*}{$\begin{array}{l}\text { Infradiaphragmatic } \\
\text { total anomalous } \\
\text { pulmonary venous } \\
\text { return }\end{array}$} & \multirow[t]{2}{*}{3} & $95 / 55$ & $55 / 40$ & \multirow[t]{2}{*}{64} & \multirow[t]{2}{*}{64} & 4 \\
\hline & & & $\overline{70}$ & $\overline{45}$ & & & No operation \\
\hline \multirow[t]{2}{*}{5} & \multirow{2}{*}{$\begin{array}{l}\text { Total anomalous } \\
\text { pulmonary venous } \\
\text { return to right } \\
\text { atrium }\end{array}$} & \multirow[t]{2}{*}{3} & $70 / 50$ & $70 / 50$ & \multirow[t]{2}{*}{61} & \multirow[t]{2}{*}{56} & 5 \\
\hline & & & $\overline{56}$ & $\overline{56}$ & & & No operation \\
\hline \multirow[t]{2}{*}{6} & \multirow{2}{*}{$\begin{array}{l}\text { Infradiaphragmatic } \\
\text { total anomalous } \\
\text { pulmonary venous } \\
\text { return }\end{array}$} & 5 & $90 / 69$ & $80 / 55$ & 69 & 62 & 6 \\
\hline & & & $\overline{70}$ & $\overline{60}$ & & & \\
\hline
\end{tabular}


In both the injected and uninjected uninflated tissue, pulmonary vascular structure was analysed using quantitative morphometric techniques. ${ }^{6-8}$ In each case, the percentage wall thickness of both arteries and veins was determined. The vessels were grouped according to their external diameter and the mean percentage wall thickness was calculated for each size range. For each case, percentage wall thickness was determined in each lobe separately. The mean external diameter and the proportion of non-muscular, partially muscular, or entirely muscularised arteries accompanying each type of peripheral airway (terminal bronchioli, respiratory broncholi, and alveolar ducts) were assessed for each lobe. The results in each lobe and, where possible, each lung were compared using Student's $t$ test.

In order to estimate the number of intra-acinar * arteries and veins the ratio of alveoli to arteries and alveoli to veins was determined in the injected tissue of cases 4 and 5 .

On the fixed specimens the lumen diameter of the extrapulmonary veins was measured in all except case 4. In four cases of infradiaphragmatic total anomalous pulmonary venous return the lumen diameter of the descending vertical vein was also measured. Fig. 1 indicates those extrapulmonary veins and regions of the descending vertical vein selected for histological examination. The descending vertical vein was thick

${ }^{\star}$ An acinus is all lung tissue distal to a terminal bronchiolus. walled for a distance of $1.5 \mathrm{~cm}$ proximal to its entering the porta hepatis in case 2 , and the lumen was occluded in this region in case 6 . In both cases, a serial reconstruction was made of this part of the descending vertical vein.

All histological sections of lung and venous tissue were $4 \mu \mathrm{m}$ thick and stained with haematoxylin and eosin and with Miller's elastic stain counterstained with van Gieson's stain. The serial sections were all stained with Miller's elastic stain.

\section{Results}

On microscopical examination of the lung tissue, in all cases the alveoli appeared normal, were mature, and not saccular. The lymphatic channels were considerably dilated in all sections of lung tissue examined. In the injected specimens, the two postmortem arteriograms and one lobar venogram showed a normal branching pattern and no stenoses.

\section{INTRAPULMONARY ARTERIES}

In all cases the media of the intrapulmonary arteries appeared thicker than normal. In each case, in both injected and uninjected tissue, mean percentage arterial medial thickness in arteries of all sizes was significantly greater than is normal at 5 hours of age in all parts of the lung examined (Fig. 2 and 3). The increase in muscularity was similar in different parts of
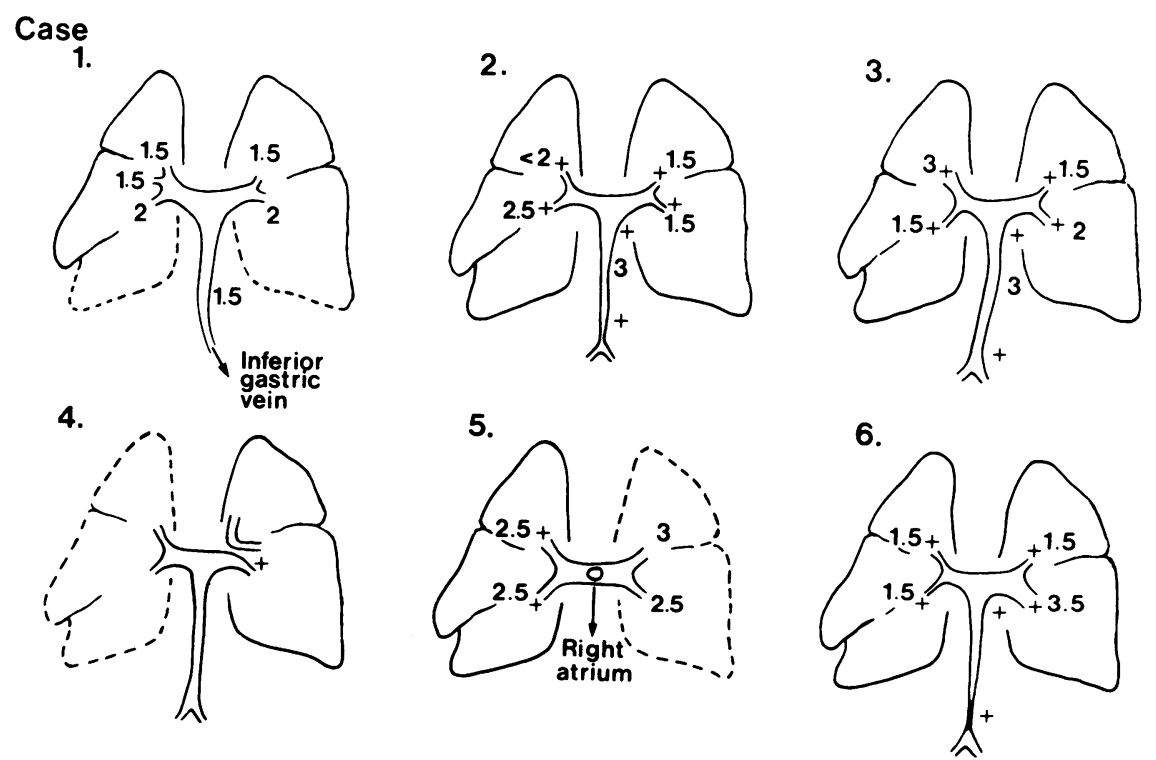

Fig. 1 Diagram to show the type of total anomalous pulmonary venous return and the lumen diameter of the extrapulmonary veins and descending vertical vein $(\mathrm{mm})$. The lobes of lung examined histologically are indicated by a continuous outline to the lung, and those lobes not examined histologically are indicated by an interrupted line. The extrapulmonary and descending vertical veins examined histologically are shown by $a+$. 
the same lung and in the two lungs of the same case where the tissue was available for such a comparison to be made. Microscopical examination of the lung tissue from all cases and the quantitative studies on the injected lung specimens of cases 4 and 5 showed that muscle was present in smaller and more peripheral arteries than is normal (Fig. 3 and 4).

Intimal proliferation was not seen.

The mean external diameter of arteries accompanying peripheral airways in both injected and uninjected tissue was within normal limits for age. Within each case there was no significant regional variation in intra-acinar arterial size. In all cases the number of intra-acinar arteries appeared normal on general microscopical examination. More precisely, the ratio of alveoli to arteries was normal in the injected tissue of cases 4 and 5, being $10 \cdot 4$ and $9 \cdot 4$, respectively.

\section{INTRAPULMONARY VEINS}

Like the arteries, the intrapulmonary veins seen in all the sections of lung tissue examined microscopically from all six cases showed an increase in wall thickness of both pre- and intra-acinar vessels. The intra-acinar veins had a thickened media and a well-defined external elastic lamina, and resembled arteries (Fig. 5). The media of the large preacinar veins consisted of thick continuous elastic fibres separated by an increased amount of smooth muscle (Fig. 6). A thick

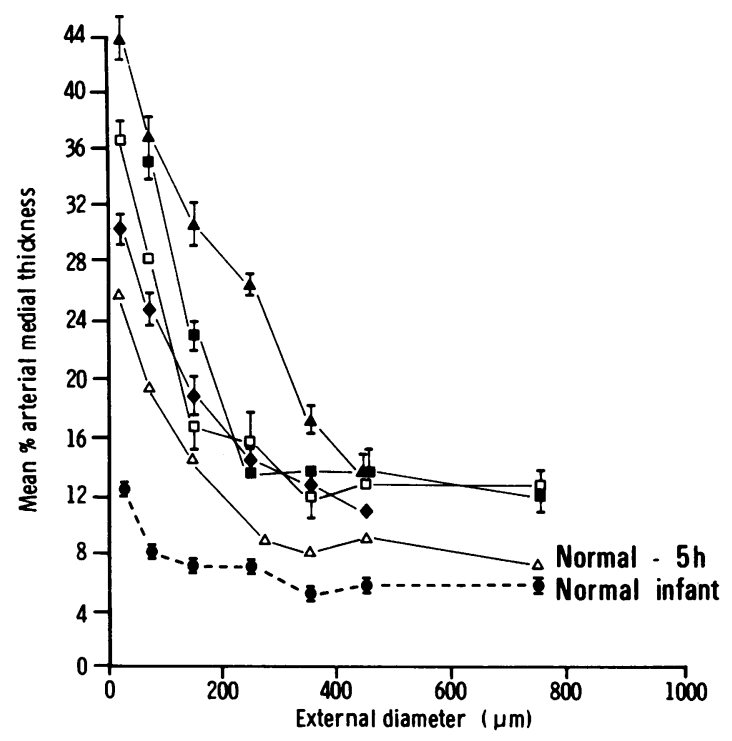

Fig. 2 Uninjected lung tissue. Mean percentage arterial medial thickness related to external diameter $(\mu \mathrm{m})$, showing the increase in muscularity in four cases of total anomalous pulmonary venous return as compared with the normal at 5 hours and in older infants. Case $1 \square-\square$; case $2 \triangle-\triangle$; case $3 \square-\square$; case $6 \bullet-\triangle$;SEI.

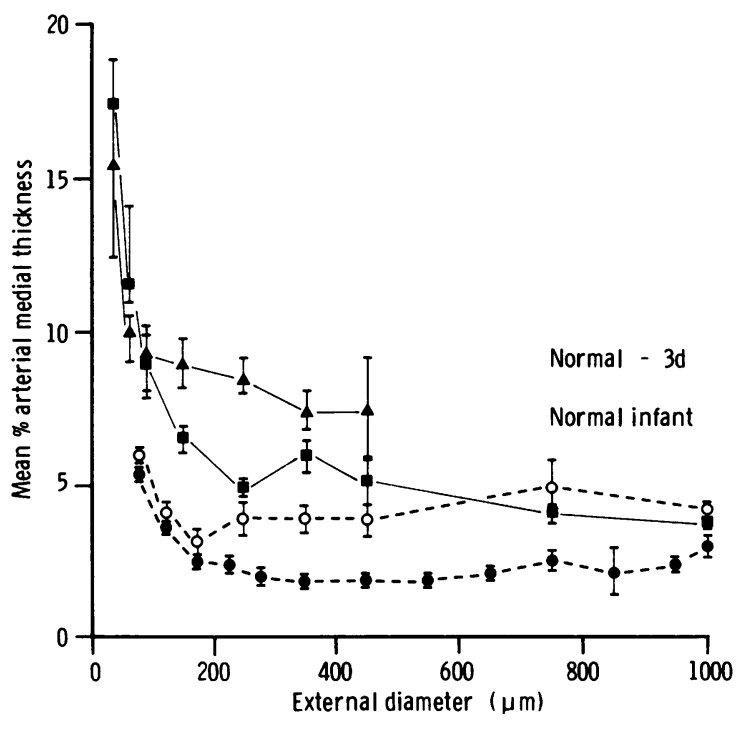

Fig. 3 Injected lung tissue. Mean percentage arterial medial thickness related to external diameter $(\mu \mathrm{m})$ showing the increase in muscularity in cases 4 and 5 as compared with the normal at 3 days and in older children.

Case 4 A- $\triangle$; case $5 \square-\square$; SEI.

adventitia was composed of densely arranged collagen fibres.

Like the arteries, intimal proliferation was not found in the intra-acinar veins in any of the cases. By contrast, the preacinar intrapulmonary veins showed intimal proliferation in two cases, being found in both lower lobes of case 3 , and in the right upper and lower lobe of case 5 .

Mean percentage vein wall thickness was significantly greater than normal in all cases, using uninjected tissue in five cases and injected tissue in case 5 (Fig. 7). The normal tissue used for comparison included that of stillborn fetuses aged 36 and 38 weeks and full-term infants up to 6 hours of age. In normal infants mean percentage vein wall thickness does not change significantly after birth. ${ }^{9}$ At 1 to 6 days (the age at which the children in the study group died) muscularity would certainly not be greater than in these controls. In the cases of total anomalous pulmonary venous return analysis of the tissue available showed no significant difference in vein wall muscularity between different lobes or between different lungs of the same case.

Accurate counts of the number of small intrapulmonary veins related to the number of alveoli were possible only in the injected specimen of case 5, where the alveolar to vein ratio was normal at $4: 1$. The 


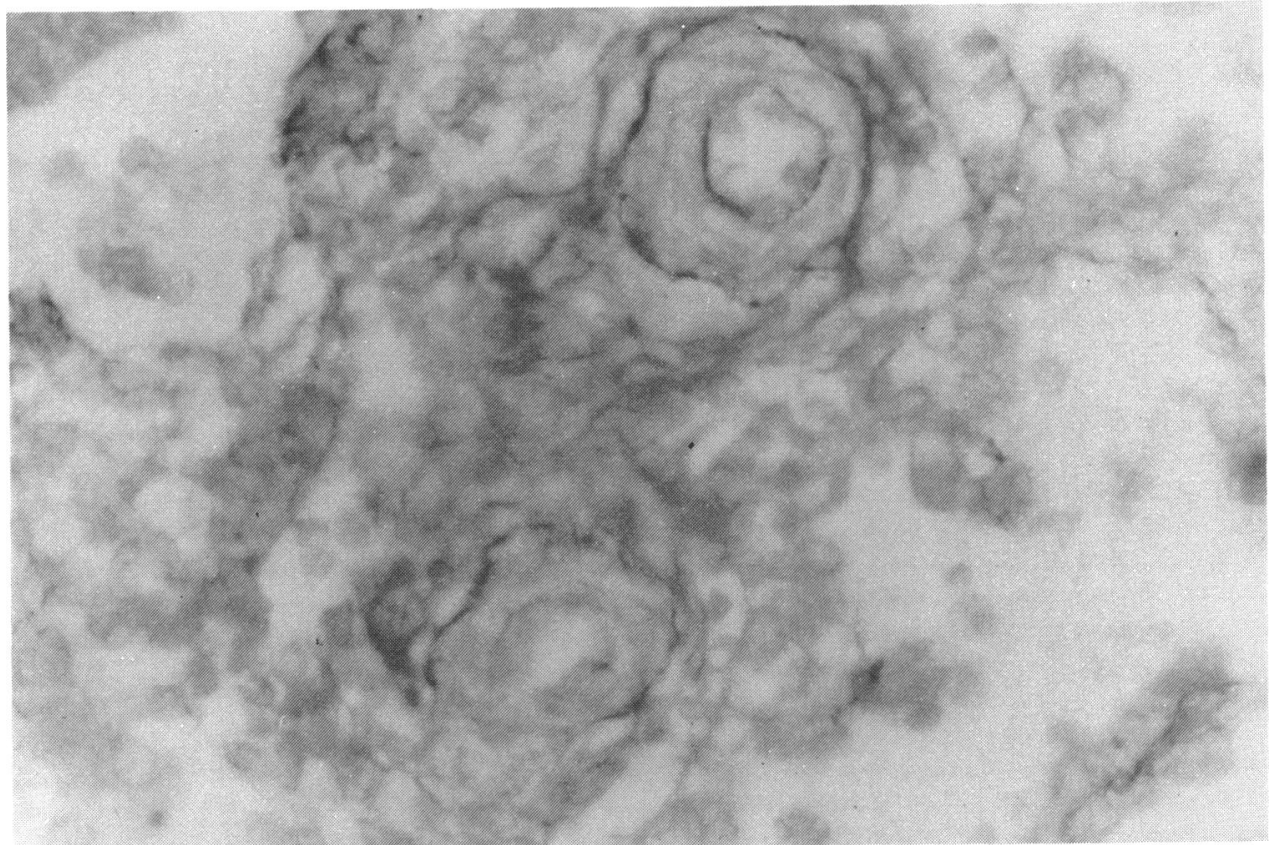

Fig. 4 Photomicrograph of thick walled muscular alveolar wall arteries. (Original magnification $\times 540$.)

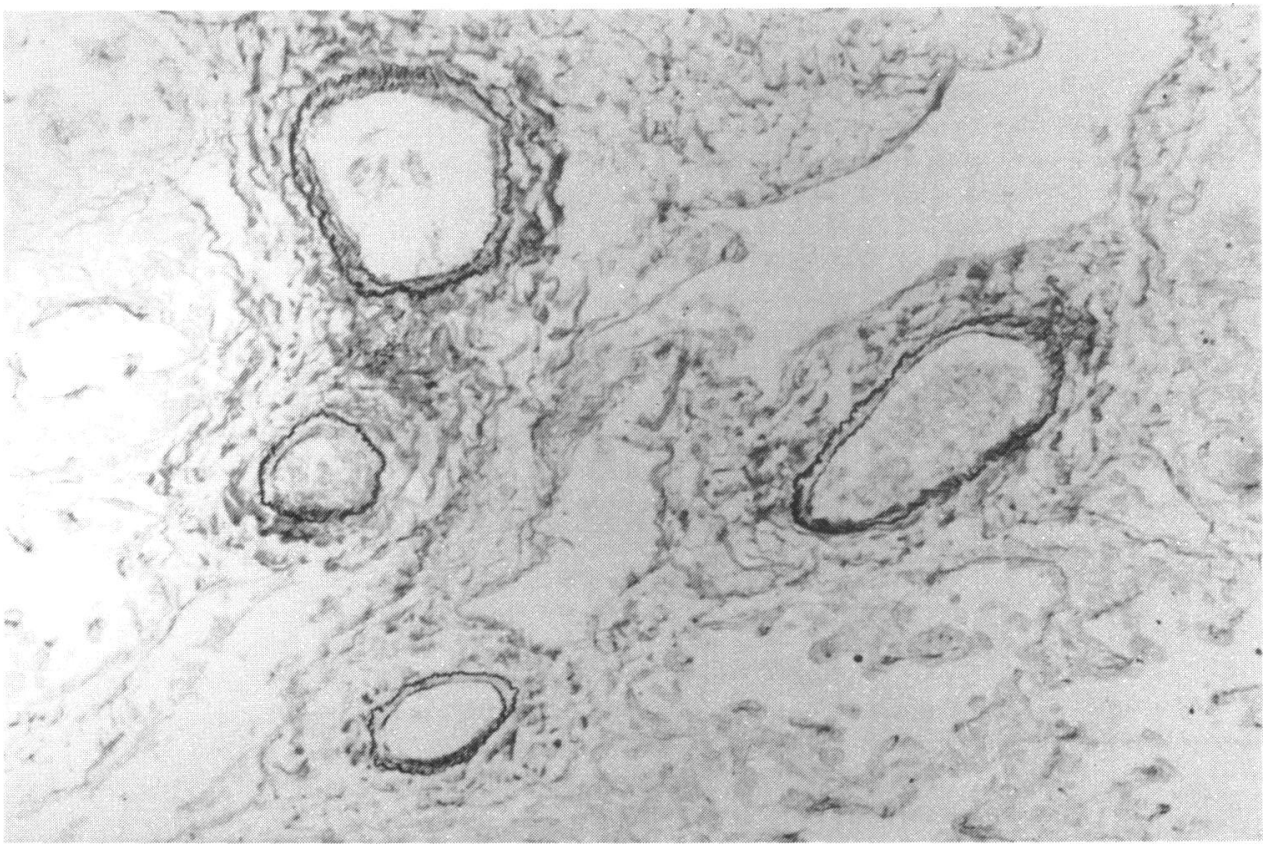

Fig. 5 Photomicrograph of thick walled muscular small pulmonary veins which resemble arteries. (Original magnification $\times 367$.) 


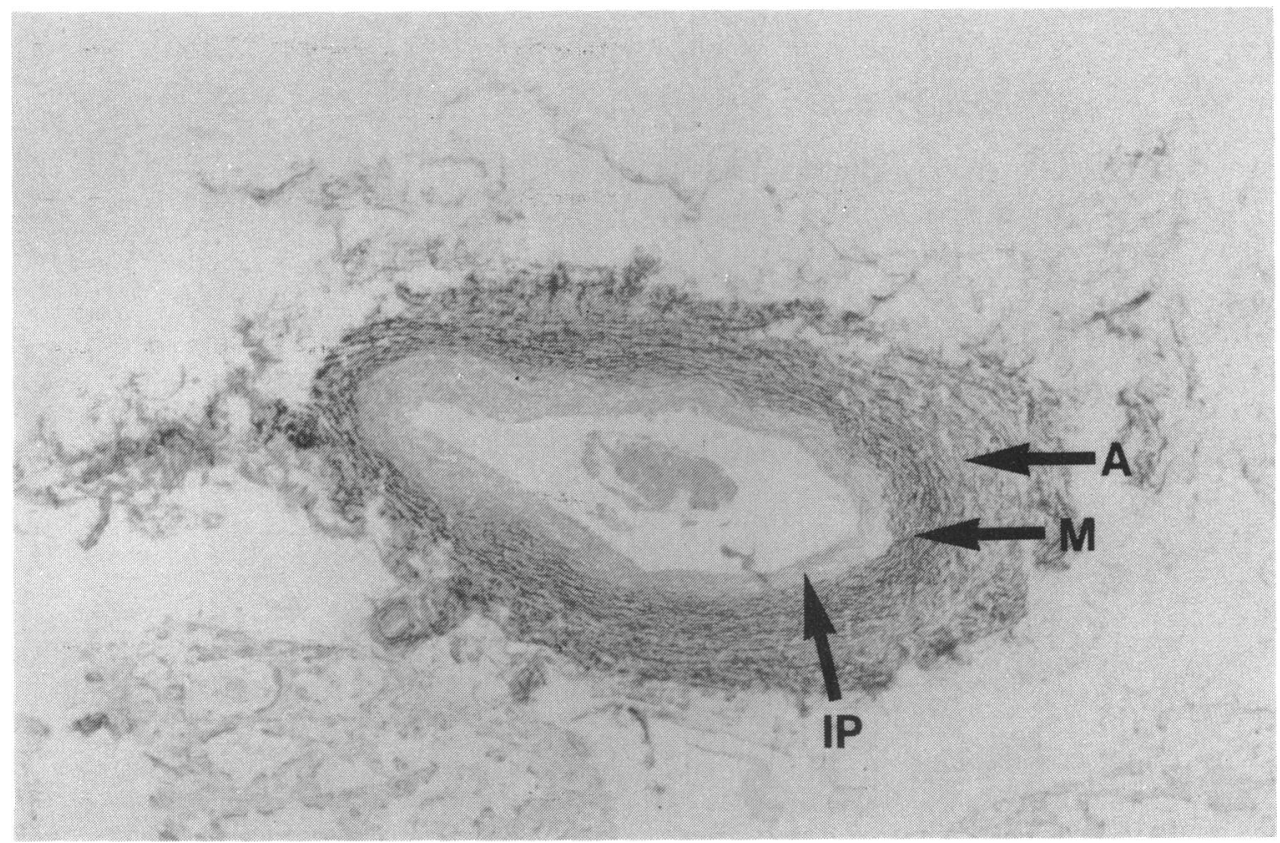

Fig. 6 Photomicrograph of a large preacinar pulmonary vein with a thickened media $(M)$ and adventitia $(A)$ and intimal proliferation $(I P)$. (Original magnification $\times 38)$.

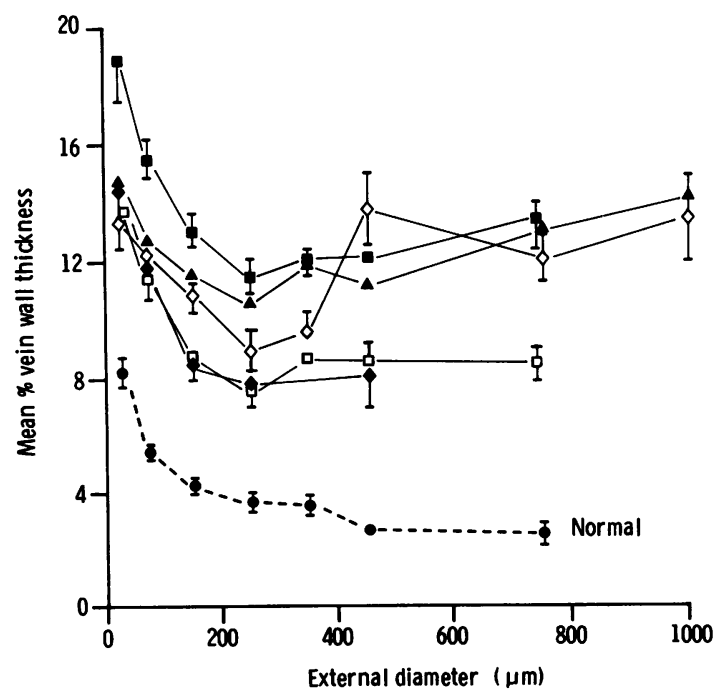

Fig. 7 Mean percentage vein wall thickness in uninjected tissue, related to external diameter $(\mu m)$, showing an increase in vein wall thickness in five cases of total anomalous pulmonary venous return as compared with the normal of similar age.

Case $1 \square$; case $2 \square-\square$; case $3 \diamond-\diamond$; case $4 \downarrow \rightarrow$; case $6 \Delta-\Delta ; S E I$. 
right upper lobe venogram in case 5 showed a normal lumen diameter of 1 to $1.8 \mathrm{~mm}$ in the veins situated midway between the hilum and pleural surface.

\section{PULMONARY VEIN-BRONCHIAL VEIN \\ ANASTOMOSES}

Connections between dilated thick walled pulmonary veins and thin walled bronchial veins were identified more readily than in the normal lung in both uninjected and injected tissue. In addition, injecting the pulmonary veins filled enlarged bronchial veins with injection material more frequently than is normal (Fig. 8).

\section{EXTRAPULMONARY VEINS}

In the normal fixed specimen the lumen diameter of the undistended pulmonary veins during the first week of life is 2 to $3 \mathrm{~mm}$. Histologically, the wall has a thin media and an adventitia containing a layer of myocardial fibres (Fig. 9a). In the five cases of total anomalous pulmonary venous return in which the extrapulmonary veins were examined the veins varied in size within and between cases, were generally smaller than normal, and only in case 5 were all the veins at least $2 \mathrm{~mm}$ in diameter (Fig. 1). Macroscopically, the wall was abnormally thick in the veins of cases 2,3 , and 6 . Microscopically, the thick extrapulmonary veins in these three cases and in case 5 showed similar structural features (Fig. 9b). Within the wall three or four thick continuous elastic fibres separated by muscle cells could be distinguished and this layer resembled the media of a normal extrapulmonary vein. Occasionally, this layer was immediately beneath the intima, but more commonly it lay beneath several layers of elastic fibres with interspersed muscle cells and collagen (Fig. 9b). Because the adventitia contained long, thick elastic fibres, the walls of all the extrapulmonary veins examined contained 12 to 20 layers of elastic fibres. In cases 2,3 , and 6 the extrapulmonary veins contained eccentric areas of amorphous intimal tissue (Fig. 9b). No myocardial muscle fibres were seen in any of the extrapulmonary veins.

\section{DESCENDING VERTICAL VEIN}

In four of the five children with infradiaphragmatic total anomalous pulmonary venous return, the descending vertical vein was patent throughout except in case 6 when it was occluded for a distance of $4 \mathrm{~mm}$ immediately proximal to its connection with the portal system. In all except case 1 , the descending vertical vein had a diameter of 3 to $3.5 \mathrm{~mm}$ throughout all or most of its length. In case 1 it measured only 1 to $2 \mathrm{~mm}$ in diameter. The microscopical features were similar in

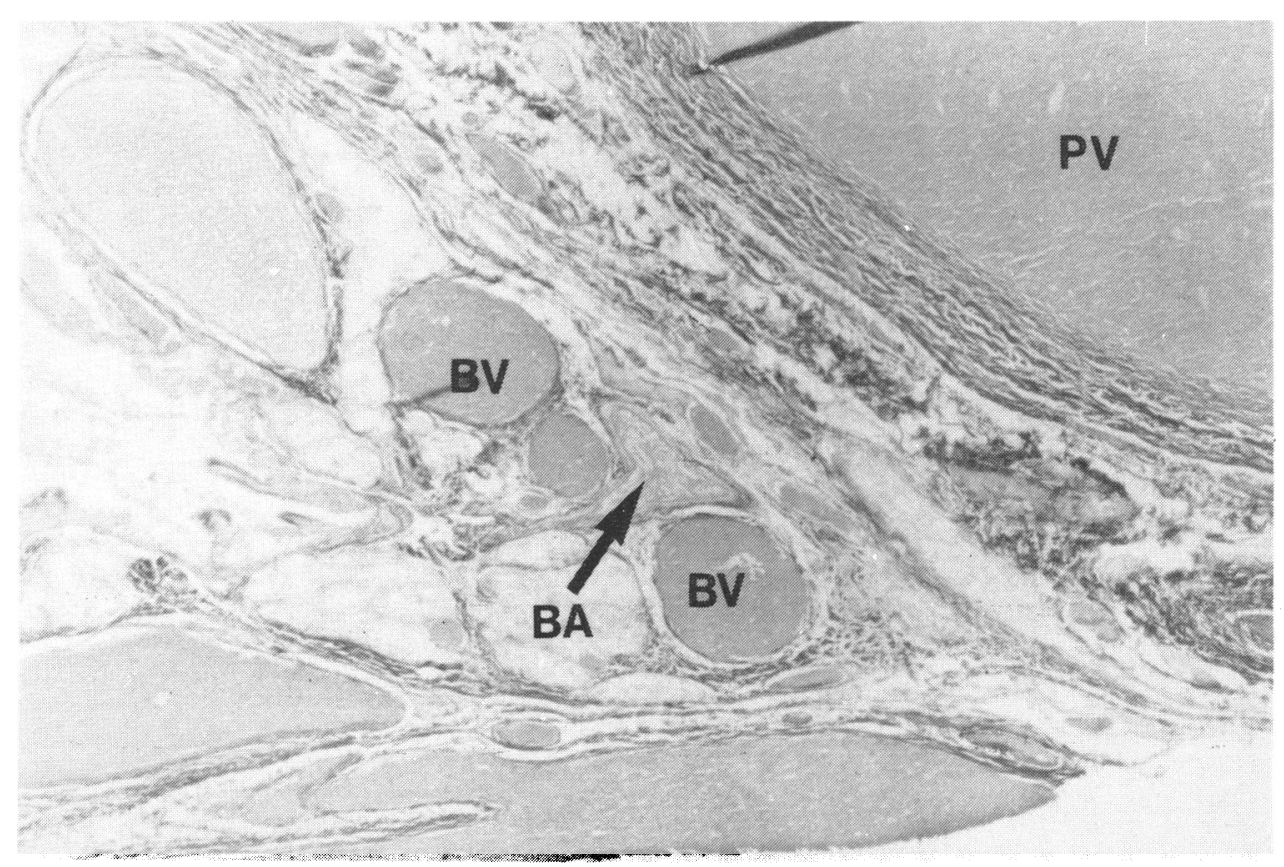

Fig. 8 Photomicrograph of injected lung tissue in case 4. Injection of the pulmonary veins (PV) filled the bronchial veins $(B V)$. BA, bronchial artery. (Original magnification $\times 38$.) 


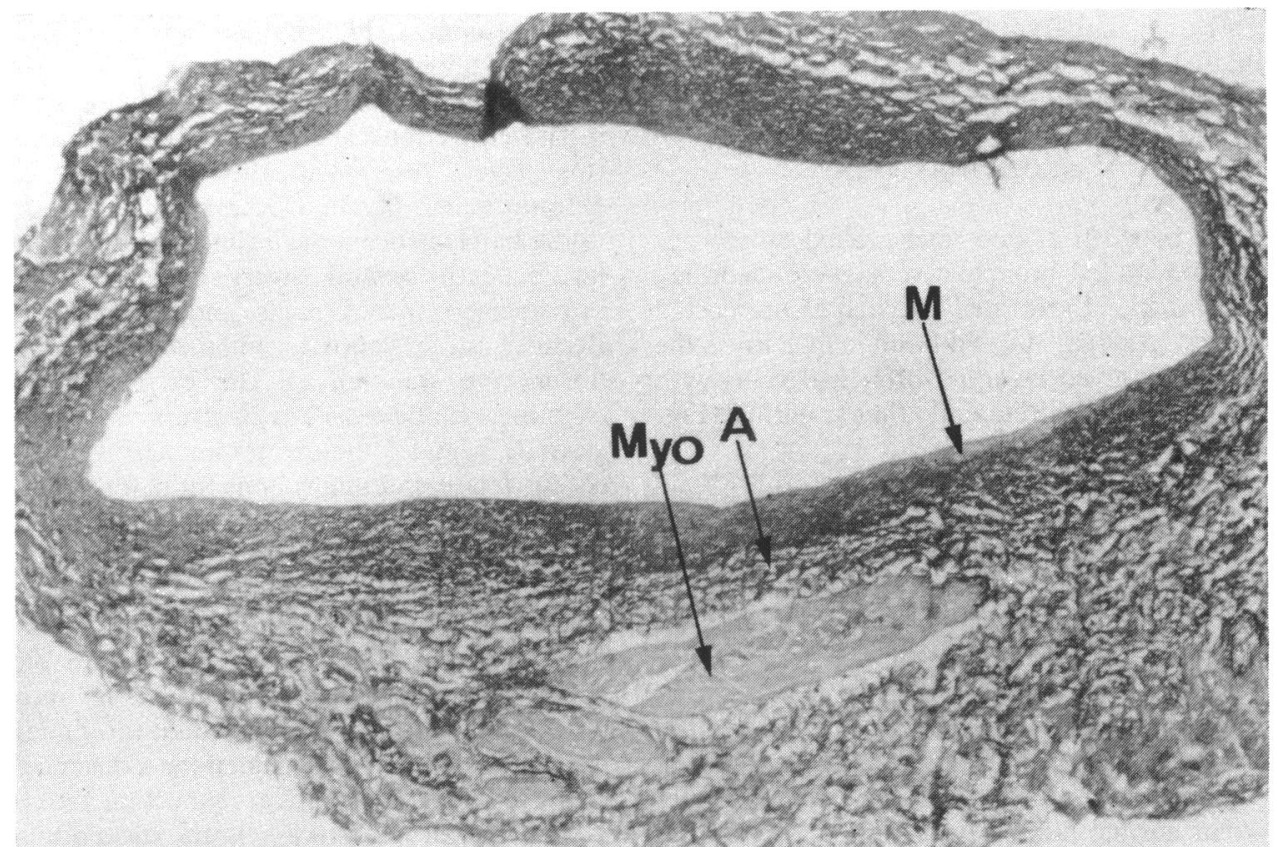

(a)

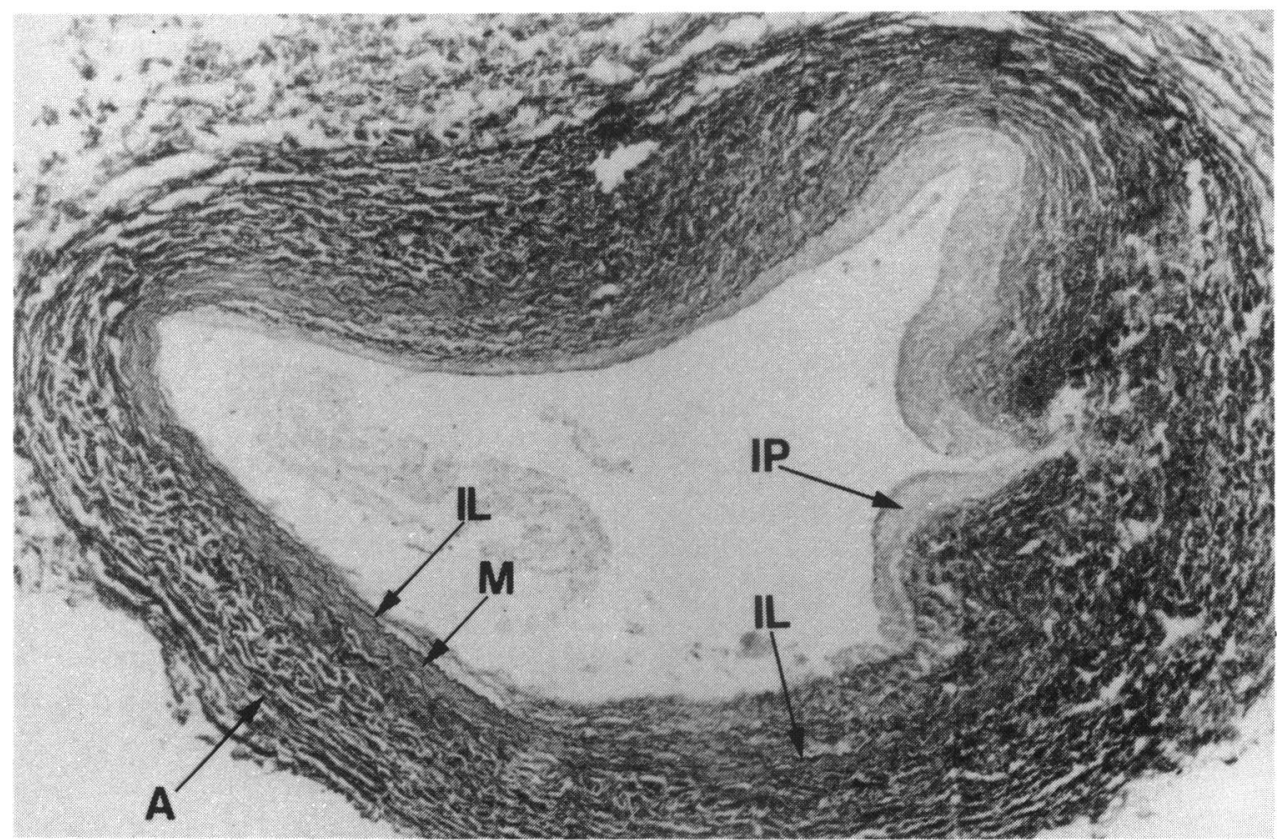

(b)

Fig. 9 (a) Photomicrograph of the wall of an extrapulmonary vein from a normal lung at the age of 3 days. Muscle layer $(M)$ is thin. Myocardial fibres $(M y o)$ are present in the adventitia $(A)$. (Original magnification $\times 38$.) (b) Photomicrograph of the left lower lobe pulmonary vein in case 3. Internal elastic lamina $(I L)$ demarcates the muscle layer $(M)$ from the intimal proliferation $(I P)$. The adventitia $(A)$ is abnormally thick and dense and contains much elastin. (Original magnification $\times 38$.) 
all three specimens examined histologically. Beneath the endothelium lay a thin layer composed of three to four long unfragmented elastic fibres interspersed with smooth muscle cells. A thick adventitia was composed of dense collagen, and long continuous elastic fibres were concentrated in the outer half of the wall. No myocardial fibres were present. In case 2 a serial reconstruction showed that as the vein approached the diaphragm the wall became thicker, and small eccentric unobtrusive mounds of intimal tissue projected into the lumen. In case 6 these changes were more pronounced until the descending vertical vein became occluded with collagen fibres (Fig. 10).

In all four children who had undergone a surgical repair the anastomosis between the left atrium and common pulmonary vein was wide and measured 7 to 8 $\mathrm{mm}$ in diameter in the fixed specimen.

\section{Summary of pathological findings}

Of the five patients with infradiaphragmatic total anomalous pulmonary venous return, the descending vertical vein was patent in four, the extrapulmonary veins were generally smaller than normal in all, and the vein wall was abnormally thick and showed intimal proliferation in three cases. In the one case of total anomalous pulmonary venous return to the right atrium the extrapulmonary veins were normal in size and thickness, though the histological features were similar to those in cases of the infradiaphragmatic type of drainage. The extrapulmonary veins were composed of an increased amount of collagen and elastin, without myocardial fibres in the adventitia.

Pulmonary arterial medial thickness was increased, and muscle was present in smaller more peripheral arteries than is normal for age. The intra-acinar arteries were normal in size and appeared to be normal in number. In all cases the mean percentage vein wall thickness was increased in pre- and intra-acinar veins. Intimal proliferation occurred in the large pre-acinar veins of two of the six cases, though in no case was it present in all parts of the lung examined. The number of intra-acinar veins appeared normal. Anastomoses between small pulmonary and bronchial veins present in the normal lung were prominent in uninjected material, and in the one injected specimen the pulmonary veins frequently filled the bronchial veins also. Within the group of six cases, there was no relation between the amount of pulmonary arterial or venous muscularity and age.

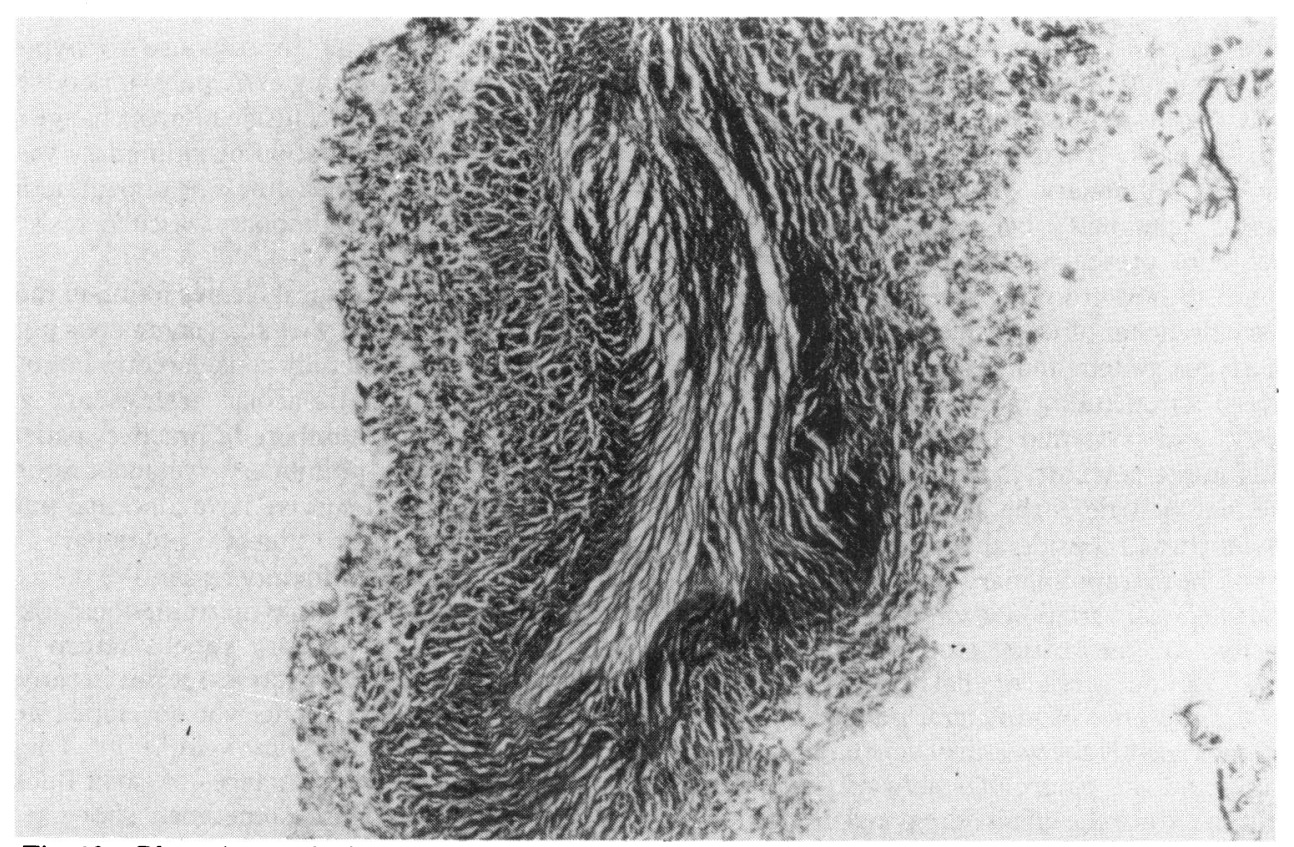

Fig. 10 Photomicrograph of a descending vertical vein occluded by fibrous tissue just above the diaphragm. (Original magnification $\times 38$.) 


\section{Discussion}

In six patients dying with obstructed total anomalous pulmonary venous return during the first six days of life, an increase in the muscularity of the intrapulmonary arteries and veins indicates that obstruction to pulmonary venous outflow was present before birth. The deposition of increased amounts of smooth muscle, elastin, and collagen in both extra- and intrapulmonary veins, and the narrowing or even occlusion of the descending vertical vein by collagen rather than by amorphous acellular material suggest that obstruction to pulmonary venous return had been present for a considerable time before birth. Patients with the infradiaphragmatic type of total anomalous pulmonary venous return are usually considered to have obstruction to pulmonary venous return because of the length and relatively small cross-sectional area of the anomalous venous pathway and the resistance to blood flow through the hepatic sinusoids when the ductus venosus is closed. In the present study, the size of the descending vertical vein appeared to obstruct flow in three of the five cases with infradiaphragmatic total anomalous pulmonary venous return. In the one patient in whom the pulmonary veins drained anomalously to the right atrium, an anatomical site of obstruction was not identified. The structural change within the lungs and the severity of the pulmonary hypertension were, however, as severe in all three patients without demonstrated anatomical obstruction as in those with obstruction.

Despite partial or even total obstruction to pulmonary venous drainage in all six cases the lungs continued to grow in utero and after birth sustained life for up to six days. It has been suggested that in the presence of pulmonary venous hypertension the anastomotic channels between pulmonary and bronchial veins present in the normal lung widen to allow blood to flow from the pulmonary veins to the pulmonary branches of the bronchial veins and thence into the azygos system and superior vena cava. ${ }^{10} 11$ In the arterial circulation, anastomioses between the pulmonary and systemic circulations occur more frequently in the newborn than in the older lung ${ }^{12}$ and the same may be true of the venous systems. In some patients there was a considerable variation in the lumen diameter of the extrapulmonary veins, but there was no significant regional variation in either arterial or venous muscularity in the cases studied. Ferencz and Dammann ${ }^{13}$ found arterial medial hypertrophy in both lungs in the presence of unilateral pulmonary venous obstruction. Possibly the wealth of venous anastomoses in the lung and the pleurohilar network of bronchial veins help to reduce the effect of regional differences in the severity of obstruction to pulmonary venous outflow. The pronounced dilatation of the lymphatic channels in all cases in the present series attests to the increased drainage of fluid from the lung by this route.

In the present study intrapulmonary arterial and venous muscularity was increased: Using the same techniques of quantitative morphometric analysis, a similar increase in muscularity has been found in a slightly older group of children dying with obstructed total anomalous pulmonary venous return during the first three months of life. ${ }^{6}$ The structural changes in the veins were more severe in the present study, particularly in the preacinar veins which were very thick walled and showed intimal proliferation in two cases. Most of the structural changes present in both arteries and veins were, however, potentially reversible in both series of cases. Newfeld et al. ${ }^{5}$ studied an older group of patients aged 5 days to 12 years (median 3 months), and reported more advanced pulmonary vascular disease. In that series, 12 of the 13 children aged 1 month or less had arterial cellular intimal proliferation and four had occlusive intimal fibrosis, though these changes were not necessarily found in more than a few of the arteries examined. The present study indicates that children with total anomalous pulmonary venous return who present to the cardiologist during the first days of life may have been born with significant pulmonary vascular disease. These findings help to explain the sudden and unexplained increases in pulmonary arterial pressure and resistance which occur in some young infants immediately after repair of the anomaly. ${ }^{14}$ The increase in muscularity probably encourages both arteries and veins to vasoconstrict in response to hypoxia and acidosis, making the lung extremely vulnerable despite the absence of severe occlusive intimal change in young infants. The administration of pulmonary vasodilator substances such as tolazoline ${ }^{14}$ or dopamine has been found to lower the pulmonary vascular resistance on such occasions.

The type of pathological change found in the arterial walls of young infants with total anomalous pulmonary venous return is generally considered to be reversible. In addition, the intra-acinar arteries are generally normal in size and number. In practice, patients with total anomalous pulmonary venous return who undergo repair and survive have a normal pulmonary vascular resistance unless pulmonary venous obstruction is present for any reason. 1516

Several published follow-up studies on patients with total anomalous pulmonary venous return who had undergone a satisfactory surgical repair in early infancy include one or more patients who developed stenosis of at least one extrapulmonary vein..$^{121718}$ The present study includes several instances of small thick walled extrapulmonary veins, sometimes showing intimal fibrosis. The lumen of the vessels was narrowed because the vessel was intrinsically small. There was no 
instance of narrowing by external compression or by a localised stricture or a diaphragm. The normal pulmonary vein is thin walled and readily distensible. Abnormally thick walled, small veins may fail to grow normally as the cardiac output increases with growth, encouraging further intimal proliferation and fibrosis, to give an appearance similar to that described by Friedli et al., ${ }^{18} \mathrm{Katz}$ et al., ${ }^{2}$ and Whight et al. ${ }^{15}$ in their cases. Haemodynamic studies on a group of apparently healthy survivors suggested that relative narrowing of the pulmonary veins might occur frequently, but was usually "unimportant and non-progressive". 15

Pulmonary venous stenosis has occurred after repair of the total anomalous pulmonary venous return to the coronary sinus 2151920 and to the liver. ${ }^{1}{ }^{15}{ }^{17}$ Babies with infradiaphragmatic total anomalous pulmonary venous return may, however, be particularly disposed to develop pulmonary vein stenosis. In the majority of these babies, pulmonary venous return is obstructed. Narrowing of the common pulmonary vein, as seen in three cases in the present series, may help explain the increased wall thickness of the extrapulmonary veins at birth in such children, predisposing them to further occlusive pulmonary venous change after repair. In two children with infradiaphragmatic total anomalous pulmonary venous return who developed postoperative pulmonary vein stenosis, patch angioplasty was successful initially, but the veins subsequently became restenosed. ${ }^{1}$ It may perhaps be more difficult to achieve satisfactory permanent relief of pulmonary vein stenosis in patients with total anomalous pulmonary venous return because the whole vein is small, rather than there being a localised constriction.

In a recent surgical series patients with the infradiaphragmatic type of total anomalous pulmonary venous return had a higher mortality, both early and late, than did those with other types of total anomalous pulmonary venous return. ${ }^{1}$ The present study also suggests that this group of patients is particularly vulnerable. Five of the six consecutive specimens referred for study from children dying with obstructed total anomalous pulmonary venous return during the first week of life showed the infradiaphragmatic type of pulmonary venous return. Both the intrapulmonary vessels and extrapulmonary veins showed structural abnormalities likely to increase the operative risk and predispose such patients to the development of pulmonary vein stenosis after a technically successful surgical repair.

The author wishes to thank the physicians, surgeons, and pathologists of the Brompton Hospital, Guy's Hospital, and the Hammersmith Hospital for permission to study their cases.

\section{References}

1 Turley K, Tucker WY, Ullyot DJ, Ebert PA. Total anomalous pulmonary venous connection in infancy: influence of age and type of lesion. Am F Cardiol 1980; 45: 92-7.

2 Katz NM, Kirklin JW, Pacifico AD. Concepts and practices in surgery for total anomalous pulmonary venous connection. Ann Thorac Surg 1978; 25: 479-87.

3 Gersony WM, Bowman FO Jr, Steeg CN, Hayes CJ, Jesse MJ, Malm JR. Management of total anomalous pulmonary venous drainage in early infancy. Circulation 1971; 43, suppl I: 1-19.

4 Wukasch DC, Deutsch M, Reul GJ, Hallman GL, Cooley DA. Total anomalous pulmonary venous return: review of 125 patients treated surgically. Ann Thorac Surg 1975; 19: 622-33.

5 Newfeld EA, Wilson A, Paul MH, Reisch JS. Pulmonary vascular disease in total anomalous pulmonary venous drainage. Circulation 1980; 61: 103-9.

6 Haworth SG, Reid L. A structural study of the pulmonary circulation and of the heart in total anomalous pulmonary venous return in early infancy. $B r$ Heart $\mathcal{f} 1977 ; 39$ : 80-92.

7 Hislop A, Reid L. New pathological findings in emphysema of childhood. I. Polyalveolar lobe with emphysema. Thorax 1970; 25: 682-90.

8 Davies G, Reid L. Growth of the alveoli and pulmonary arteries in childhood. Thorax 1970; 25: 669-81.

9 Hislop A, Reid L. Fetal and childhood development of the intrapulmonary veins in man-branching pattern and structure. Thorax 1973; 28: 313-9.

10 Marchand P, Gilroy JC, Wilson VH. An anatomical study of the bronchial vascular system and its variations in disease. Thorax 1950; 5: 207-21.

11 Wagenvoort CA, Wagenvoort N, Becker AE. The effect of obstructed pulmonary venous blood flow on the development of alternative pathways in the lung. $f$ Pathol 1972; 107: 21-5.

12 Wagenvoort CA, Wagenvoort N. Arterial anastomosis, bronchopulmonary arteries and pulmobronchial arteries in perinatal lungs. Lab Invest 1967: 16: 13-24.

13 Ferencz C, Dammann JF Jr. Significance of the pulmonary vascular bed in congenital heart disease. $\mathrm{V}$. Lesions of the left side of the heart causing obstruction of the pulmonary venous return. Circulation 1957; 16: 104656.

14 Shinebourne EA, Jones ODH, Denison DM, Lincoln C, Haworth SG. Growth and remodelling of the pulmonary circulation in congenital heart disease: clinical implications. In: Godman M, ed. Paediatric cardiology. vol. 4. Edinburgh, London: Churchill Livingstone, 1981: 71-80.

15 Whight CM, Barratt-Boyes BG, Calder AL, Neutze JM, Brandt PWT. Total anomalous pulmonary venous connection. Long-term results following repair in infancy. F Thorac Cardiovasc Surg 1978; 75: 52-63.

16 Macartney FJ, Taylor JFN, Graham GR, de Leval M, Stark J. The fate of survivors of cardiac surgery in infancy. Circulation 1980; 62: 80-91.

17 Fleming WH, Clark EB, Dooley KJ, et al. Late complications following surgical repair of total anomalous 
pulmonary venous return below the diaphragm. Ann Thorac Surg 1979; 27: 435-9.

18 Friedli B, Davignon A, Stanley P. Infradiaphragmatic anomalous pulmonary venous return. Surgical correction in a newborn infant. 7 Thorac Cardiovasc Surg 1971; 62: 301-6.

19 Gathman GE, Nadas AS. Total anomalous pulmonary venous connection: clinical and physiologic observations on 75 pediatric patients. Circulation 1970; 42: 143-54.
20 Lucas RV Jr, Anderson RC, Amplatz K, Adams P Jr, Edwards JE. Congenital causes of pulmonary venous obstruction. Pediutr Clin North Am 1963; 10: 781-836.

Requests for reprints to Dr S G Haworth, Department of Paediatric Cardiology, The Hospital for Sick Children, Great Ormond Street, London WC1N 3JH. 